C2020. This manuscript version is made available under the CC-BY-NC-ND 4.0 license http://creativecommons.org/licenses/by-nc-nd/4.0/

\title{
Amino acid recognition by a fluorescent chemosensor based on cucurbit[8] uril and acridine hydrochloride
}

Weitao Xu, ${ }^{a}$ Huaming Feng, ${ }^{a}$ Weiwei Zhao, ${ }^{a}$ Chunhua Huang, ${ }^{b}$ Carl Redshaw, ${ }^{\mathrm{c}}$ Zhu Tao ${ }^{a}$ and Xin Xiao ${ }^{a^{*}}$

${ }^{a}$ Key Laboratory of Macrocyclic and Supramolecular Chemistry of Guizhou Province, Guizhou University, Guiyang 550025, China.

${ }^{b}$ National Research Center for Geoanalysis, China Geological Survey, Beijing 100037, China.

${ }^{c}$ Department of Chemistry and Biochemistry, University of Hull, Hull HU6 7RX, U.K.

*Corresponding author. Tel./fax: +86 15519089928

E-mail address: gyhxxiaoxin@163.com (X. Xiao).

\section{Graphical abstract}

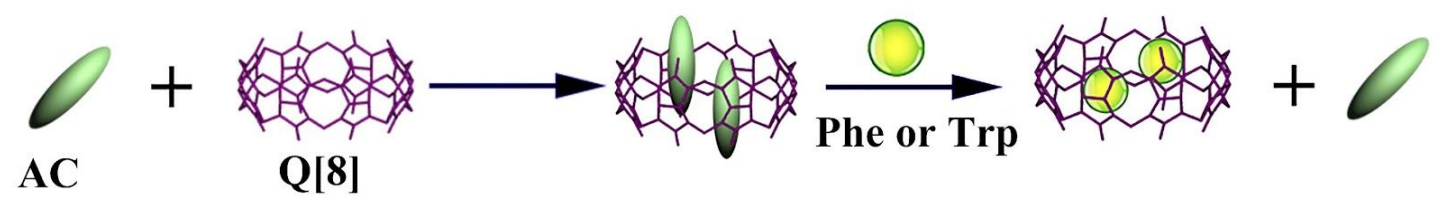

A new fluorescent chemosensor comprised of cucurbit[8]uril (Q[8]) and acridine hydrochloride $(\mathrm{AC})$ has been designed for the recognition of amino acids. As a result of this study, the fluorescence detection of five amino acids in a single system has been accomplished.

\begin{abstract}
A new fluorescent chemosensor comprised of cucurbit[8]uril (Q[8]) and acridine hydrochloride $(\mathrm{AC})$ has been designed and utilized for the recognition of amino acids. The AC was encapsulated by the Q[8] cavity and formed a 1:2 host-guest inclusion complex both in solution (aqueous) and in the solid-state. Whilst free AC is known to be strongly fluorescent, this strong fluorescence was quenched in the inclusion complex Q[8]-AC. This non-fluorescent complex Q[8]-AC was capable of serving as a fluorescence "off-on" probe, and was able to recognize either $L$-Phe or $L$-Trp via the competitive interaction between $L$-Phe or $L$-Trp. Moreover, the $\mathrm{pH}$ responsive nature of the probe allowed for the detection of basic amino acids, namely $L$-Arg, $L$-His, or $L$-Lys). As a result, a fluorescence method for the detection of five amino acids using a single system has been developed.
\end{abstract}

Keywords: chemosensor, cucurbit[8]uril, recognition, "off-on” probe, $\mathrm{pH}$-responsive 


\section{Introduction}

Amino acids are of huge biological significance, and are not only constituents of peptides, proteins, and alike but also play pivotal roles in the transport of materials and in biosynthesis [1,2]. Arginine (Arg) for example plays a central physiological role in a variety of transformations including cell division, gene regulation, healing of wounds and the release of hormones [3-5]. Moreover, Arg is used to treat diseases resulting from endocrine and high ammonia reactions [6,7]. Similarly, histidine (His) is critical for many enzymatic processes [8], whilst it has been reported that decreases in His levels are observed in patients suffering from lung cancer [9-13]. In the case of lysine, it is linked to the Krebs-Henseleit cycle and to polyamine synthesis [14,15], whilst high levels of lysine in the plasma and urine are indicators of congenital metabolic disorders, for example cystinuria or hyperlysinemia [16,17]. The amino acid phenylalanine (Phe) is extensively employed both in the food and pharmaceutical industries. Examples of the use of Phe include as an intermediate in the production of anti-cancer drugs, as a nutritional additive, and as an additive in food and drink [18]. Finally, from a biological perspective, tryptophan (Trp) plays an important role in human metabolism [19] and is associated with the likes of diabetes and nerve disorders [20]. The selective recognition of amino acids is thus highly desirable for a variety of medicinal reasons.

We note that a range of traditional detection methods for amino acids have previously been developed, including high-performance liquid chromatography, ion-exchange chromatography as well as gas chromatography [21-23]. However, such detection methods suffer from a number of deficiencies, namely that they are somewhat complicated, not cheap, can be awkward to use, exhibit poor selectivity, lack precision and sensitivity, and also suffer from a lack of reproducibility [24]. This has led to recent increased interest in the potential of host-guest chemistry, and a boost to progress in the area of molecular recognition [25-27]. This increased interest in aqueous host-guest chemistry has led to the availability of analyte responsive host-dye systems based on macrocycles or so-called host-dye fluorescence indicator displacement (FID) systems. Such FID systems are now attracting the interest of researchers as agreeable alternatives to the more traditional chemosensors [28,29].

Cucurbit $[n]$ urils $(\mathrm{Q}[n] \mathrm{s})$, a family of synthetic macrocycles, are capable of binding amines over a wide affinity range $\left(10^{3}\right.$ to $\left.10^{12} \mathrm{M}^{-1}\right)$ in aqueous solution, and for this reason have attracted interest for both molecular recognition and in molecular devices [30-39]. Over the past 10 years or so, $\mathrm{Q}[n] \mathrm{s}$ and derivatives thereof have been shown to interact with a number of specific amino acids, peptides, and proteins [40-48]. However, given that amino acids have in common the same types of functional groups, namely carboxylic/ $\mathrm{CO}_{2} \mathrm{H}$ and amino/ $\mathrm{NH}_{2}$ groups, the manufacture of sensors capable of detecting specific amino acids with both significant sensitivity and selectivity remains a key target. Reports on the use of cucurbit[ $n]$ uril-based host-dye fluorescence indicator displacement systems for amino acid detection remain 
scant. In 2011, Quintana reported an electrochemical sensor which employed the host-guest interactions of Q[8], and was applied to the determination of tryptophan in 'real' samples displaying reasonable accuracy and precision [49]. In 2017, our group reported two fluorescent probes based on two alkyl-substituted cucurbit[6]urils and a cationic vinylpyridine containing dye. These probes were capable of recognizing lysine and methionine versus a number of other $\alpha$-amino acids in aqueous solution [50]. More recently, Yang et al. synthesized an ambient temperature phosphorescent (RTP) cyclodextrin-Q[6]-co-wheeled [4]rotaxane, and utilized it for the highly specific sensing of Trp. It was noted that the strong green emission associated with the RTP was quenched in the presence of Trp, whereas when other physiologically relevant amino acids were added, no such quenching was evident [51].

Herein, a cucurbit $[n]$ uril-based host-dye fluorescence indicator has been assembled from $\mathrm{Q}[8]$ and acridine hydrochloride (AC). The interaction between $\mathrm{Q}[8]$ and $\mathrm{AC}$ was studied by a number of spectroscopic methods including fluorescence, UV-vis and ${ }^{1} \mathrm{H}$ NMR spectroscopy. From the data accumulated, a 1:2 host-guest inclusion complex was identified. Interestingly, free $\mathrm{AC}$ is known to be strongly fluorescent, however the fluorescence was quenched for this Q[8]-AC inclusion complex. To this Q[8]-AC system, 20 natural amino acids were added; phenylalanine (Phe) and tryptophan (Trp) both resulted in a significant amplification of the green fluorescence intensity of the inclusion complex, while basic amino acids exhibited blue fluorescence. These results demonstrated the ability to detect five amino acids in a single system using a fluorescence method.

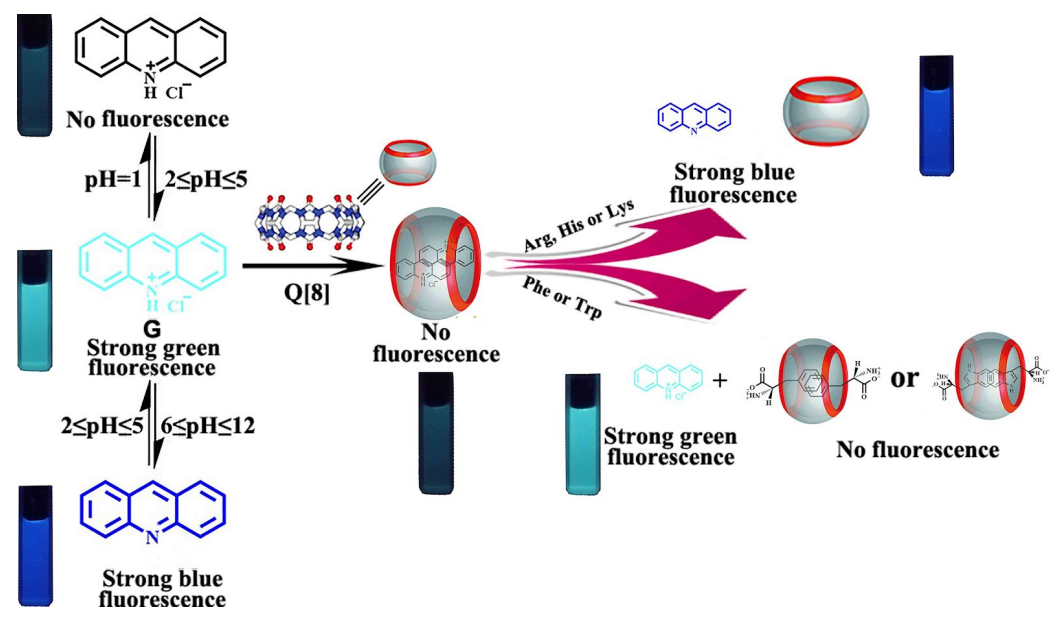

Scheme 1. A feasible process for the fluorescence indicator displacement via the host-guest interactions.

\section{Results and Discussion}

\subsection{Binding behavior between $A C$ and $Q[8]$}

The binding behavior between $\mathrm{Q}[8]$ and $\mathrm{AC}$ was initially studied by employing UV-vis absorption and fluorescence spectroscopy. The gradual addition of Q[8] results in a gradual decrease in the maximum absorbance of $\mathrm{AC}$ (at a fixed $\mathrm{AC}$ concentration of $2 \times 10^{-5} \mathrm{~mol} \cdot \mathrm{L}^{-1}$ ) at $355 \mathrm{~nm}$ (Figure 1A) until the ratio of the host-guest reached 0.5 . This suggests a 1:2 host-guest inclusion complex is formed 
between the Q[8] and AC (Figure 1B), and a continuous variation Job's plot (Figure 1C) was also consistent with a stoichiometry of $1: 2$.
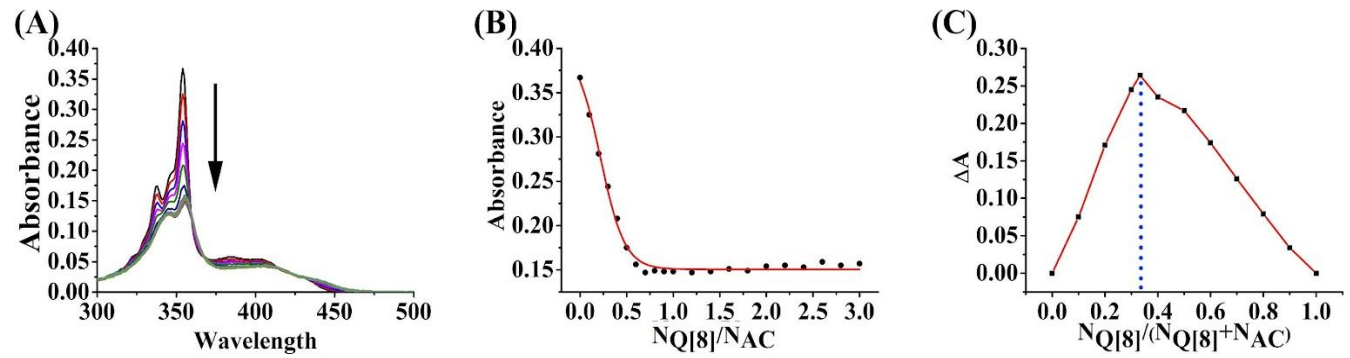

Figure 1. (Color online) (A) Absorption of $\mathrm{AC}\left(2 \times 10^{-5} \mathrm{~mol} \cdot \mathrm{L}^{-1}\right)$ upon addition of increasing amounts $(0,0.1$, $0.2 \cdots \cdots .0 .9,1.0,1.2,1.4 \cdots \cdots 2.6,2.8$, and 3.0 equiv) of $\mathrm{Q}[8]$ in aqueous $\mathrm{HCl}$ solution $(\mathrm{pH}=4.0)$; (B) the concentration and absorbance $v s . \mathrm{N}_{\mathrm{Q}[8]} / \mathrm{N}_{\mathrm{AC}}$ plots in aqueous $\mathrm{HCl}$ solution $(\mathrm{pH}=4.0)$; (C) the corresponding $\Delta \mathrm{A}-\mathrm{N}_{\mathrm{Q}[8]} /\left(\mathrm{N}_{\mathrm{Q}[8]}+\mathrm{N}_{\mathrm{AC}}\right)$ curves in aqueous $\mathrm{HCl}$ solution $(\mathrm{pH}=4.0)$.

Given that the guest AC possesses an amino group, and that protonation/deprotonation or changes in solution $\mathrm{pH}$ are likely to influence the photophysical properties of $\mathrm{AC}$, it is necessary to evaluate the influence of the inclusion of $\mathrm{AC}$ by $\mathrm{Q}[8]$ versus free $\mathrm{AC}$ on the $\mathrm{pKa}$. The effect of free $\mathrm{AC}$ and the presence of $\mathrm{Q}[8]$ ( 0.5 equiv) versus $\mathrm{pH}(1-12)$ were tracked using UV-visible and fluorescence spectroscopy. As can be seen in Figure S1-S2, over the $\mathrm{pH}$ range 1.05 to 4.00, $\mathrm{AC}$ exists in the protonated form, and the fluorescence intensity of AC increases with increasing $\mathrm{pH}$. By contrast, over the $\mathrm{pH}$ range 5.99 to 11.95 , the fluorescence intensity of $\mathrm{AC}$ decreases and this is accompanied by a blue shift on increasing $\mathrm{pH}$. When comparing the absorbance-pH and fluorescence-pH curves for $\mathrm{AC}$ and that of the inclusion complex (Figure S3), it was decided for this study to conduct the experiments at $\mathrm{pH} 4.0$, where $\mathrm{AC}$ exists in the protonated form.

As mentioned above, AC $\left(2 \times 10^{-5} \mathrm{~mol} \cdot \mathrm{L}^{-1}\right)$ displays a robust green fluorescence possessing a maximum emission at $478 \mathrm{~nm}$ in solution (aqueous) at $\mathrm{pH} 4.0$ (Figure 2A), whilst the interaction with Q[8] led to a significant weakening of the emission intensity. Also, the continued addition of Q[8] resulted in a further weakening in the emission intensity of $\mathrm{AC}$ until the $\mathrm{Q}[8]-\mathrm{AC}$ ratio reached 1:2 (Figure 2B), which revealed the emergence of a robust supramolecular complex. The extinguishing of fluorescence is attributed to photo-induced electron transfer from the carbonyl oxygen of Q[8] to the excited state of AC [52]. Moreover, using the Job's plot method, as shown in Figure 2C, it was observed that the maximum peak appeared at a mole fraction of 0.33 , which corresponds to a 1:2 binding stoichiometry for $\mathrm{Q}[8]$ to $\mathrm{AC}$, and this is compatible with the results acquired from the UV-vis absorption spectra. Furthermore, the isothermal titration calorimetry experiment was carried out at $25^{\circ} \mathrm{C}$ to better understand the host-guest interactions between Q[8] and AC. The experimental results afforded an association constant $\left(K_{a}\right)$ value of $2.870 \times 10^{8}$ $\mathrm{M}^{-2}$, and $\Delta H^{\circ}$ and $T \Delta S^{\circ}$ values indicating that the interactions between the Q[8] host and $\mathrm{AC}$ guest appear to be driven by favorable enthalpy changes, accompanied by small negative (unfavorable) entropy changes (Figure S4). 

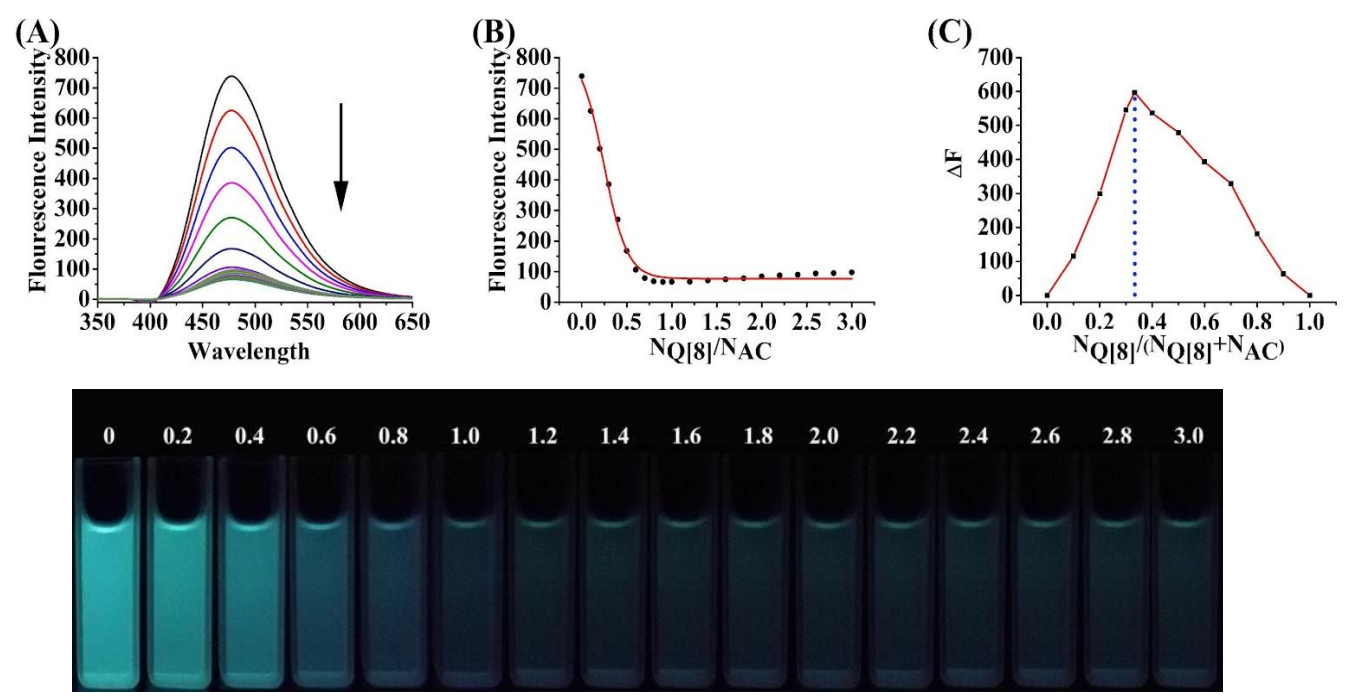

Figure 2. (A) Fluorescence emission of $\mathrm{AC}\left(2 \times 10^{-5} \mathrm{~mol} \cdot \mathrm{L}^{-1}\right)$ following increasing amounts $(0,0.1,0.2 \cdots \cdots \cdot 0.9,1.0$, $1.2,1.4 \cdots \cdots \cdot 2.6,2.8,3.0$ equiv) of $\mathrm{Q}[8]$ in $\mathrm{HCl}_{\mathrm{aq}}$ solution $(\mathrm{pH}=4.0)$; (B) the concentration and fluorescence $v s$. $\mathrm{N}_{\mathrm{Q}[8]} / \mathrm{N}_{\mathrm{AC}}$ plots in aqueous $\mathrm{HCl}$ solution $(\mathrm{pH}=4.0)$; (C) the corresponding $\Delta \mathrm{F}-\mathrm{N}_{\mathrm{Q}[8]} /\left(\mathrm{N}_{\mathrm{Q}[8]}+\mathrm{N}_{\mathrm{AC}}\right)$ curves in $\mathrm{HCl}$ solution $(\mathrm{pH}=4.0)$. (D) Photographs of $\mathrm{AC}\left(2 \times 10^{-5} \mathrm{~mol} \cdot \mathrm{L}^{-1}\right)$ upon addition of growing amounts $(0,0.2,0.4 \cdots \cdots \cdot 2.6$, 2.8, 3.0 equiv) of $\mathrm{Q}[8]$ under UV light (365 $\mathrm{nm})$.

On using a fixed amount of AC and gradually increasing the amount of Q[8] present, the binding behaviour was followed by ${ }^{1} \mathrm{H}$ NMR spectroscopy (Figure 3). Following the addition of Q[8], the proton resonances associated with the guest shifted upfield ( $0.99 \mathrm{ppm}$ for proton $\mathrm{H}_{\mathrm{a}}, 0.65 \mathrm{ppm}$ for proton $\mathrm{H}_{\mathrm{b}}, 0.57 \mathrm{ppm}$ for proton $\mathrm{H}_{\mathrm{c}}, 0.65 \mathrm{ppm}$ for proton $\mathrm{H}_{\mathrm{d}}$, and $0.04 \mathrm{ppm}$ for proton $\mathrm{H}_{\mathrm{e}}$ ), which suggested that these guest protons are included within the Q[8] cavity. These results combined with those above allowed us to predict a plausible interaction model in which the AC molecules completely enter the cavity of Q[8], see Figure 3 (insert). The application of MALDI-TOF mass spectrometry, see Figure S5, also provided evidence consistent with the formation of a 1:2 host-guest complex, with intense signals at 1689.022, corresponding to $\left[(\mathrm{Q}[8]-2 \mathrm{AC})-2 \mathrm{Cl}^{-}\right]^{+}$.

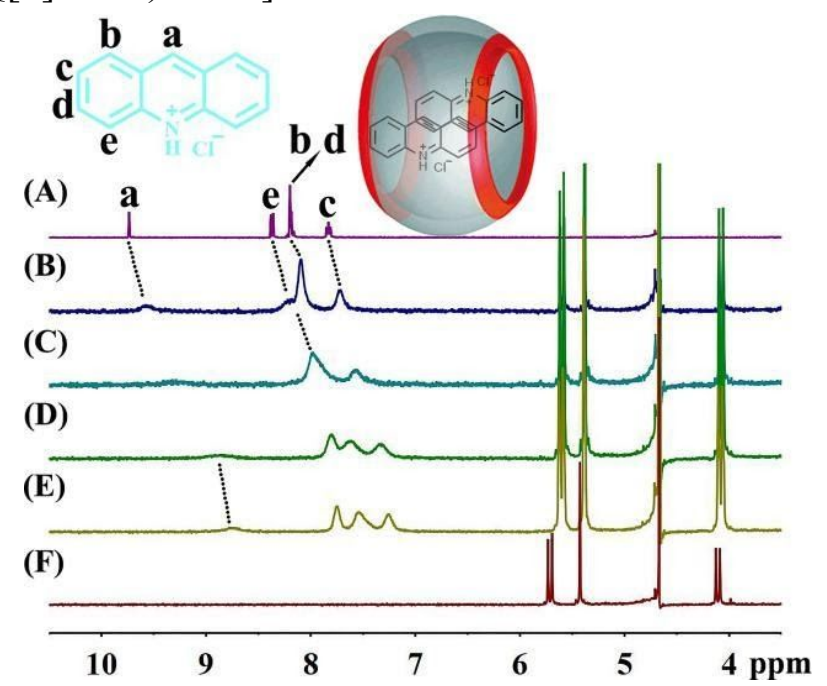

Figure 3. Combination of $\mathrm{AC}$ and $\mathrm{Q}[8]$ at $25{ }^{\circ} \mathrm{C}:{ }^{1} \mathrm{H}$ NMR spectra $\left(400 \mathrm{MHz}, \mathrm{D}_{2} \mathrm{O}, \mathrm{pD}=4.0\right)$ of $\mathrm{AC}\left(\mathrm{ca} .2 \times 10^{-5}\right.$ $\mathrm{mol} \cdot \mathrm{L}^{-1}$ ) with no $\mathrm{Q}[8](\mathrm{A})$, with 0.17 equiv. of Q[8] (B), with 0.42 equiv. of Q[8] (C), with 0.69 equiv. of Q[8] (D), with 1.04 equiv. of Q[8] (E) and neat Q[8] (F).

In addition, we obtained single crystals of AC2@Q[8]. Since the solubility of 
$\mathrm{Q}[8]$ in neutral aqueous solutions is poor, the crystallization of $\mathrm{Q}[8]-\mathrm{AC}$ was performed in an aqueous solution of $\mathrm{HCl}(6.0 \mathrm{M})$ via the introduction of $\left[\mathrm{CdCl}_{4}\right]^{2-}$. The structure is shown in Figure 4, where two AC guest molecules are located within the host Q[8] cavity, forming a 1:2 stoichiometric host-guest inclusion complex, which agrees with the host-guest solution studies. Close inspection revealed that although two AC guest molecules are located in the Q[8] cavity, they assume different inclusion conformations in the structure. For one of the two inclusion complexes (Figure 4A), $\pi \cdots \pi$ interactions between the two AC guest molecules in the $\mathrm{Q}[8]$ cavity could be observed, where the distance between two aromatic rings is $3.417 \AA$, and the angle formed between the axis of the parallel guest pair and the plane established by eight carbonyl oxygen atoms of Q[8] host is $66.20^{\circ}$. There also exist $\mathrm{C}-\mathrm{H} \cdots \mathrm{O}$ hydrogen bond interactions arising from the hydrogen of $\mathrm{AC}$ and the portal carbonyl group of $\mathrm{Q}[8](\mathrm{C} 55 \cdots \mathrm{O} 1=2.966 \AA)$, as shown in the bottom right corner of Figure 4C. For the other inclusion complex (Figure 4B), the included guest pair interact via $\pi \cdots \pi$ interactions between the two acridine rings, which is similar to that found in the abovementioned host-guest inclusion complex. Here, the distance between two aromatic rings is $3.661 \AA$, while the angle between the axis of the parallel guest pair and the plane formed by the eight carbonyl oxygen atoms of $\mathrm{Q}[8]$ host, close to vertical, is $83.80^{\circ}$. Interestingly, multiple $\mathrm{C}-\mathrm{H} \cdots \mathrm{O}$ and $\mathrm{N}-\mathrm{H} \cdots \mathrm{O}$ hydrogen bond interactions were found between the hydrogen of the guest and the portal carbonyl group of Q[8] $(\mathrm{C} 67 \cdots \mathrm{O} 14=3.187 \AA ; \mathrm{C} 68 \cdots \mathrm{O} 14=2.983 \AA$; $34 \cdots \mathrm{O} 9$ $=2.922 \AA$, and $\mathrm{N} 34 \cdots \mathrm{O} 16=3.043 \AA$ ) in this host-guest inclusion complex (see bottom upper left corner of Figure $4 \mathrm{C})$. The $\mathrm{C}-\mathrm{H} \cdots \mathrm{Cl}$ hydrogen bonds $(\mathrm{C} 3 \cdots \mathrm{Cl} 3=$ $3.372 \AA$ ) between the portal carbonyl group of Q[8] and the $\mathrm{Cl}^{-}$ions coordinated to zinc ions are present, as shown in Figure 4C.

(A)

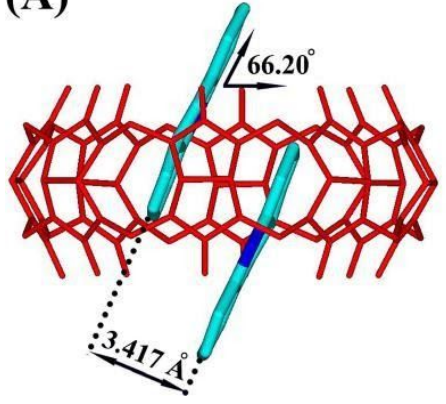

(B)

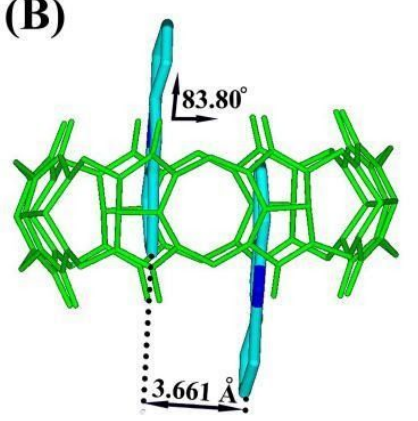

(C)

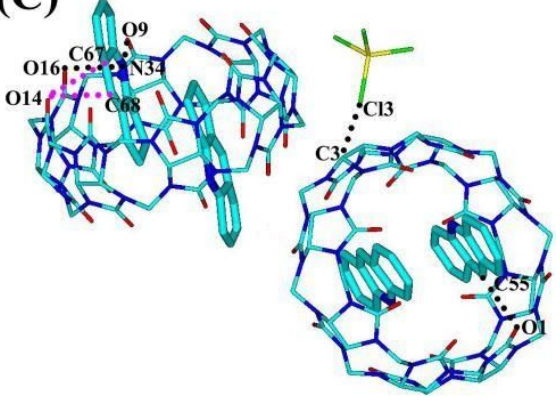

Figure 4. The molecular structure of the homo-ternary complex AC2@Q[8].

\subsection{The response of the $Q[8]-A C$ inclusion complex to different L-amino acids}

In order to detect amino acids by fluorescence, a non-fluorescent host-guest system was designed, thereby allowing for the facile "turn-on" fluorescence sensing of amino acids. As mentioned above, this new host-guest Q[8]-AC inclusion complex is non-fluorescent and exhibits good solubility in water. In order to discover whether the Q[8]-AC inclusion complex prepared herein could be employed to identify natural amino acids, a number of fluorescence experiments were conducted using each of the natural amino acids. 
Given that differing fluorescence phenomena are observed at differing $\mathrm{pH}$, the detection of $L$-amino acids was initially conducted in aqueous solution at $\mathrm{pH} 4.0$. As observed in Figures 5 and 6 , on addition of the 20 natural amino acids $\left(2 \times 10^{-4}\right.$ $\left.\mathrm{mol} \cdot \mathrm{L}^{-1}\right)$ to the $\mathrm{Q}[8]-\mathrm{AC}$ solution $\left(2 \times 10^{-5} \mathrm{~mol} \cdot \mathrm{L}^{-1}\right)$, only three basic $L$-amino acids ( $L$-Arg, $L$-His, or $L$-Lys) resulted in blue shift fluorescence changes ( $36 \mathrm{~nm}$ for $L$-Arg or $L$-Lys, and $8 \mathrm{~nm}$ for $L$-His). Moreover, when either $L$-Phe or $L$-Trp was added to the $\mathrm{Q}[8]-\mathrm{AC}$ inclusion complex, a fluorescence enhancement was evident. By contrast, on adding any of the other natural amino acids under similar conditions failed to lead to well-defined fluorescent changes. Such results strongly suggest that the Q[8]-AC inclusion complex can be employed for the discrimination of Phe, Trp, and basic amino acids ( $L$-Arg, $L$-His, or $L$-Lys) in aqueous solution.
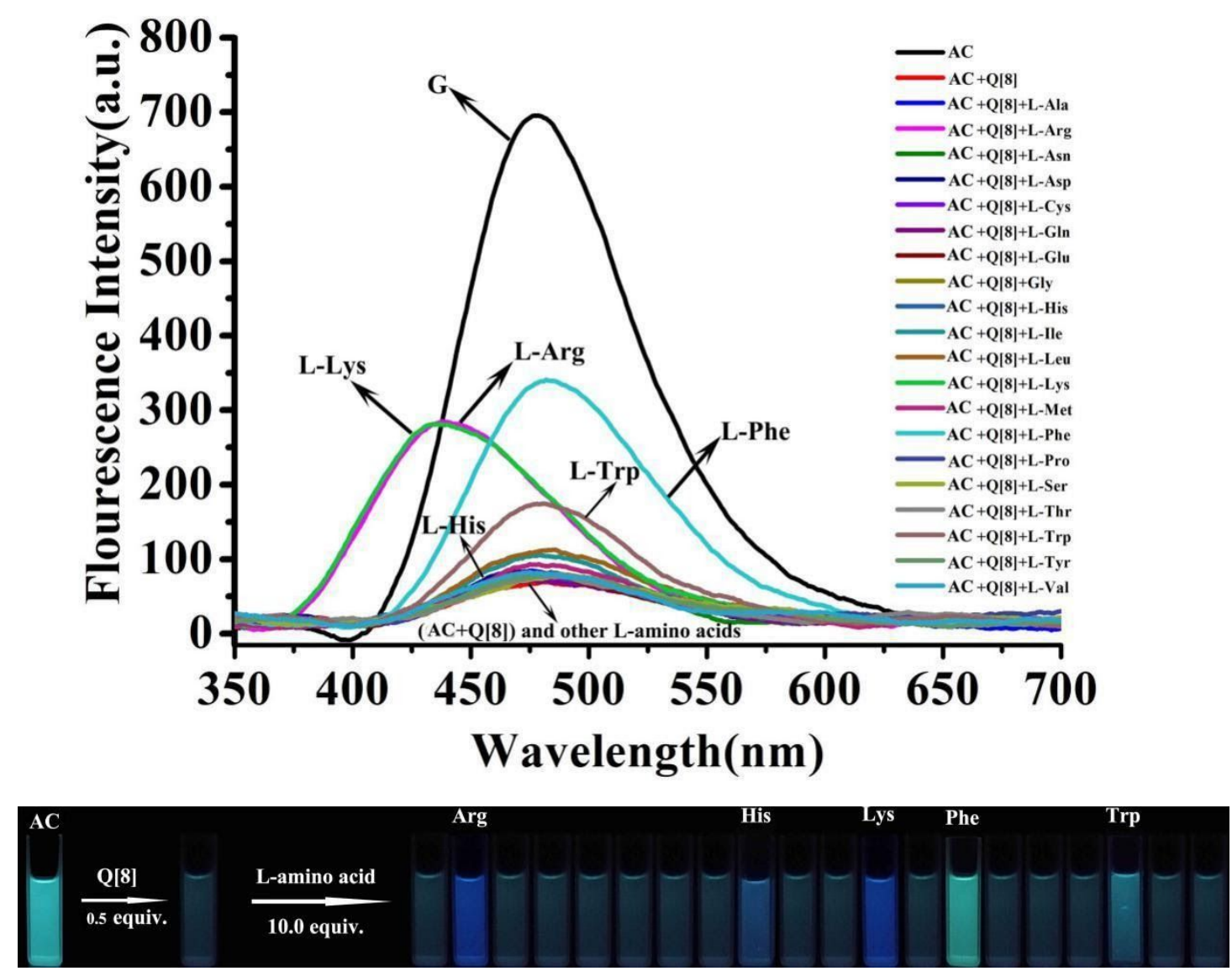

Figure 5. (top) The effect of $L$-amino acids (10 equiv. of host-guest complex) on the fluorescence response $(\lambda$ maxem $=478 \mathrm{~nm})$ of AC-Q[8] $\left(2 \times 10^{-5} \mathrm{~mol} \cdot \mathrm{L}^{-1}\right)(2: 1)$; (bottom) photographs of AC-Q[8] systems containing 10 equiv. of host-guest complex and different $L$-amino acids under UV light $(365 \mathrm{~nm})$. 


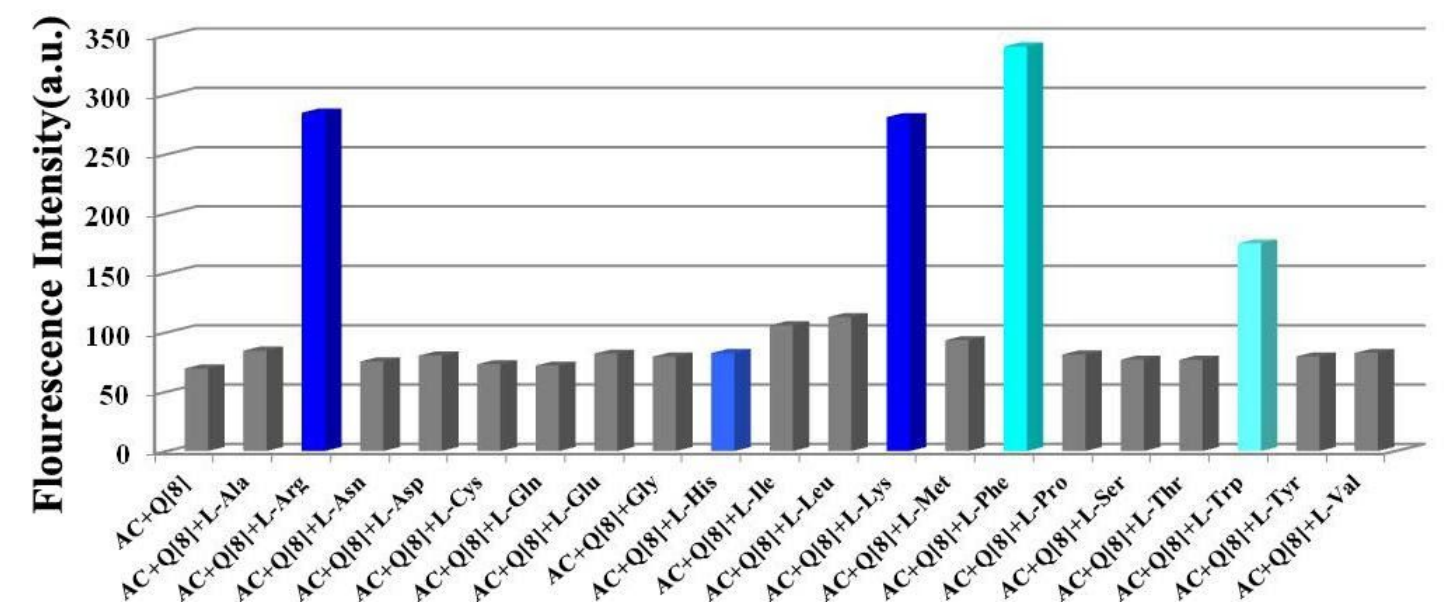

Figure 6. The effect of $L$-amino acids (10 equiv. of host-guest complex) on the fluorescence intensity ( $\lambda \mathrm{em}=478$ $\mathrm{nm})$ of $\mathrm{AC} / \mathrm{Q}[8]\left(2 \times 10^{-5} \mathrm{~mol} \cdot \mathrm{L}^{-1}\right)(2: 1)$.

A number of quantitative luminescence titration experiments were performed to further understand the recognition capability of the Q[8]-AC complex toward the above five amino acids. Firstly, different concentrations of $L$-Phe or $L$-Trp (0 to $\left.3.0 \times 10^{-4} \mathrm{~mol} \cdot \mathrm{L}^{-1}\right)$ were added to an aqueous Q[8]-AC solution, and from Figures 7 and $\mathrm{S} 6$ it is evident that the fluorescence intensity of the $\mathrm{Q}[8]-\mathrm{AC}$ complex enhanced gradually with increasing concentration of the amino acids. The significant enhancement in fluorescence for the Q[8]-AC complex in the presence of $L$-Phe or $L$-Trp, under illumination by a $365 \mathrm{~nm}$ lamp, was also evident to the naked eye. The fluorescent spectra of $D$-Phe or $D$-Trp following addition to an aqueous Q[8]-AC solution were also studied (Figures S6 and S7, ESI). In this case, it was observed that there was no selectivity for either $L$ or $D$ amino acids. Over the concentration range $2.0 \times 10^{-5}$ to $30.0 \times 10^{-5} \mathrm{~mol} \cdot \mathrm{L}^{-1}$, the detection limits (DLs) for the chosen amino acids were determined to be $2.108 \times 10^{-6} \mathrm{~mol} \cdot \mathrm{L}^{-1}$ for $L$-Phe (Figure $7 \mathrm{C}$ ), $2.100 \times 10^{-6}$ $\mathrm{mol} \cdot \mathrm{L}^{-1}$ for $D$-Phe (Figure S7C, ESI), $4.750 \times 10^{-6} \mathrm{~mol} \cdot \mathrm{L}^{-1}$ for $L$-Trp (Figure S6C, ESI), and $3.200 \times 10^{-5} \mathrm{~mol} \cdot \mathrm{L}^{-1}$ for $D$-Trp (Figure S8C, ESI).
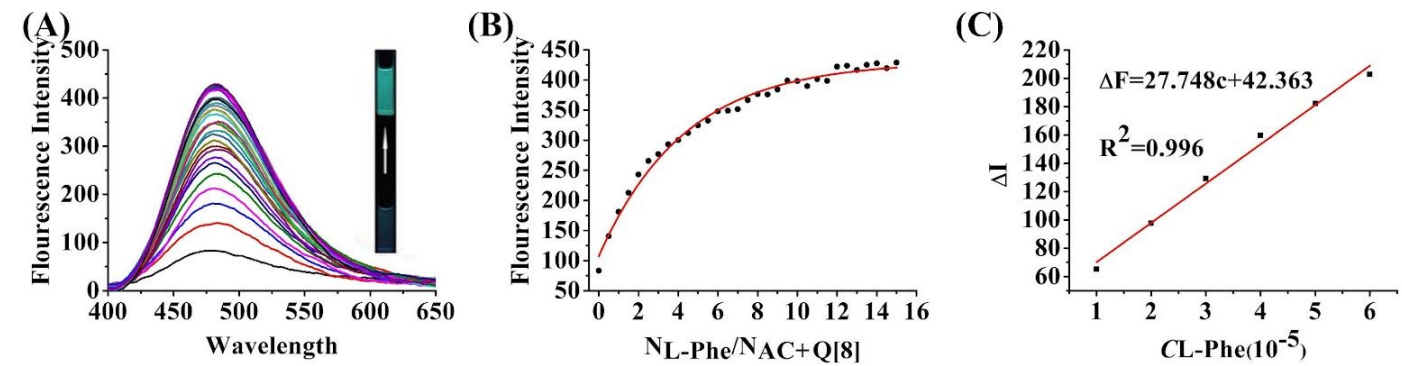

Figure 7. (A) Titration fluorescence spectra of $\mathrm{Q}[8]-\mathrm{AC}\left(2 \times 10^{-5} \mathrm{~mol} \cdot \mathrm{L}^{-1}\right)(2: 1)$ with $L$-Phe; (B) Plots of $\mathrm{N}_{\mathrm{L}-\mathrm{Phe}} / \mathrm{N}_{\mathrm{AC}}+\mathrm{Q}$ [8]; (C) Non-linear fitting curves for fluorescence intensity variation of the inclusion complex for differing concentrations of $L$-Phe.

Following the above strategy, three basic amino acids, namely $L$-Arg, $L$-His, or $L$-Lys were slowly added to an aqueous solution of Q[8]-AC. When between 0 and 5.0 equiv. of amino acids were added, no notable changes were evident in the fluorescence intensity of the Q[8]-AC system. However, on increasing the concentration of the basic amino acids, the fluorescence intensity gradually increased, 
and was accompanied by a blue shift (Figures S9 and S11). Such observations are consistent with the gradual introduction of basic amino acids ( $L$-Arg, $L$-His, or $L$-Lys) to an aqueous solution of free AC (Figures S12-S16), and could be ascribed to $\mathrm{pH}$ changes as the basic amino acids were added (Tables S1and S2).

In order to more fully understand the mechanism of recognition of the Q[8]-AC complex towards amino acids, ${ }^{1} \mathrm{H}$ NMR spectroscopy was employed using the $L$-Phe or $L$-Trp and $\mathrm{Q}[8]-\mathrm{AC}$ systems in $\mathrm{D}_{2} \mathrm{O}$ solution $(\mathrm{pD}=4)$. As shown in Figure 8, when $L$-Phe was added to the Q[8]-AC solution, the aromatic protons $\left(\mathrm{H}_{1}, \mathrm{H}_{2}\right.$, and $\left.\mathrm{H}_{3}\right)$ and the methylene proton $\left(\mathrm{H}_{4}\right)$ underwent a clear upfield shift, while proton $\mathrm{H}_{5}$ exhibited a downfield shift, which indicated that the aryl ring and methylene of the $L$-Phe can be found encapsulated within the cavity of the Q[8]. The remaining part of $L$-Phe is out of the Q[8] portal, the result being an inclusion complex between Q[8] and $L$-Phe. Then, upon adding $L$-Phe to the $\mathrm{Q}[8]-\mathrm{AC}$ inclusion complex in $\mathrm{D}_{2} \mathrm{O}$, all the proton resonances for the guest $\mathrm{AC}$ associated with the Q[8]-AC inclusion complex appeared to shift downfield $\left(\mathrm{H}_{\mathrm{a}}=0.23 ; \mathrm{H}_{\mathrm{b}}=0.21 ; \mathrm{H}_{\mathrm{c}}=0.19 ; \mathrm{H}_{\mathrm{d}}=0.21 ; \mathrm{H}_{\mathrm{e}}=0.09 \mathrm{ppm}\right.$ ) (Figure 8), which suggested that these protons were gradually exiting from the $\mathrm{Q}[8]$ cavity. Concomitantly, the protons $\left(\mathrm{H}_{1}, \mathrm{H}_{2}, \mathrm{H}_{3}\right.$, and $\left.\mathrm{H}_{4}\right)$ of $L$-Phe shifted to lower field compared to $L$-Phe in the inclusion complex. These observations demonstrated that the $L$-Phe molecule was capable of replacing the included AC molecule in the Q[8] cavity. Based on these observations, a possible interaction model between $L$-Phe and $\mathrm{Q}[8]$-AC is shown in Figure 8 (insert). For comparison, upon addition of $D$-Phe to the $\mathrm{Q}[8]-\mathrm{AC}$ inclusion complex in $\mathrm{D}_{2} \mathrm{O}$, the same phenomenon was observed (Figure $\mathrm{S} 21)$.

By using a similar approach, the mechanistic aspects of the recognition process of the Q[8]-AC complex towards $L$-Trp was also investigated in $\mathrm{D}_{2} \mathrm{O}$ solution $(\mathrm{pD}=$ 4), and was monitored by ${ }^{1} \mathrm{H}$ NMR spectroscopy. As shown in Figure S22, upon adding $L$-Trp to the $\mathrm{Q}[8]-\mathrm{AC}$ inclusion complex in $\mathrm{D}_{2} \mathrm{O}$, the included $\mathrm{AC}$ molecule was replaced by the $L$-Trp molecule in the Q[8] cavity, consistent with the observations for the Q[8]-AC- $L$-Phe system.

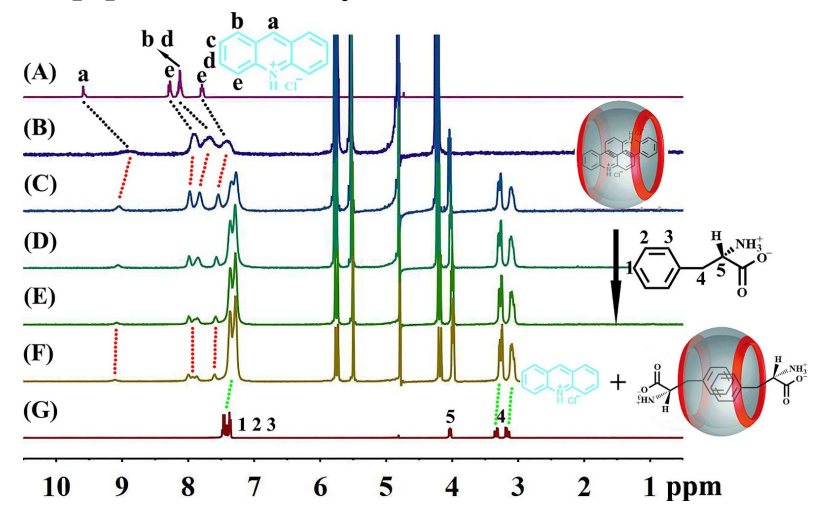

Figure 8. Titration ${ }^{1} \mathrm{H}$ NMR spectra $\left(\mathrm{D}_{2} \mathrm{O}, \mathrm{pD}=4.0\right)$ of $(\mathrm{A})$ neat $\mathrm{AC}, \mathrm{Q}[8]-\mathrm{AC}\left(2: 1,2 \times 10^{-5} \mathrm{~mol} \cdot \mathrm{L}^{-1}\right)$ in the presence of (B) 0.00, (C) 7.15, (D) 14.33, (E) 21.26, and (F) 27.78 equiv. of $L$-Phe, and (G) neat $L$-Phe.

Similarly, the crystallization of Q[8]- $L$-Phe was conducted in an aqueous $\mathrm{HCl}$ solution $(6.0 \mathrm{M})$ by introducing $\left[\mathrm{CdCl}_{4}\right]^{2-}$; the crystal structure is shown in Figure 9. The two $L$-Phe guest molecules with $\pi \cdots \pi$ interactions (the distance between two 
aromatic rings is $3.739 \AA$ ) are located in the $\underline{Q}$ [8] cavity forming a 1:2 stoichiometry host-guest inclusion complex, and the presence of the hydrogen bonds of $\mathrm{N}-\mathrm{H} \cdots \mathrm{O}$ between $L$-Phe and carbonyl oxygen of Q[8] is beneficial to the stability of the system. Multiple hydrogen-bonding interactions between Q[8]-dimers, which involve $\mathrm{O}-\mathrm{H} \cdots \mathrm{O}$ and $\mathrm{N}-\mathrm{H} \cdots \mathrm{O}$ between $L$-Phe and a portal carbonyl group $(\mathrm{O} 19 \cdots \mathrm{O} 7=2.508$ $\AA, \mathrm{N} 17 \cdots \mathrm{O} 5=2.809 \AA, \mathrm{N} 17 \cdots \mathrm{O} 7=2.963 \AA, \mathrm{N} 17 \cdots \mathrm{O} 17=2.852 \AA, \mathrm{N} 34 \cdots \mathrm{O} 12=$ $2.911 \AA$, and $\mathrm{N} 34 \cdots \mathrm{O} 17=2.968 \AA$ ) can be observed (see Figure 9).

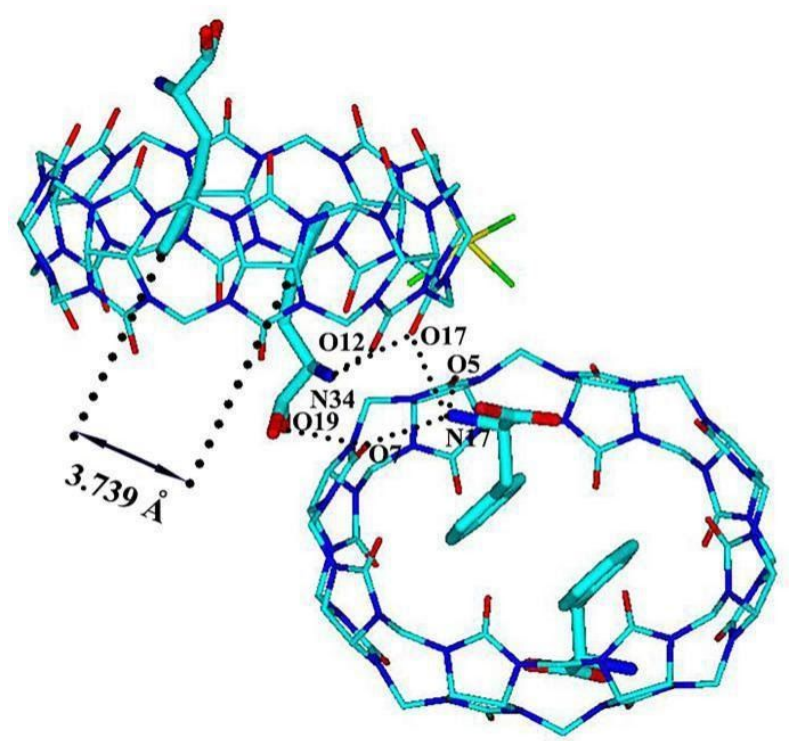

Figure 9. The molecular structure of the homo-ternary complex, L-Phe2@Q[8].

\section{Experimental Section}

\subsection{Materials}

The cucurbituril Q[8] was synthesized according to a procedure developed previously in our laboratory. Acridine and the amino acids were purchased from Aladdin (Shanghai, China). All other reagents were of analytical reagent quality and were used without any further purification. Doubly-distilled water was employed throughout.

\subsection{Measurement of absorption, mass and fluorescence spectra}

UV-visible spectra were recorded on an Agilent 8453 spectrophotometer (Agilent Technologies, Santa Clara, CA, USA) using solutions in $1 \mathrm{~cm}$ quartz cells. MALDI-TOF mass spectra were obtained using a Bruker BIFLEX III ultra-high resolution Fourier transform ion cyclotron resonance (FT-ICR) mass spectrometer using a-cyano-4-hydroxycinnamic acid as the matrix.

Fluorescence emission spectra were collated using a VARIAN Cary Eclipse spectrofluorometer (Varian, Inc., Palo Alto, CA, USA). Stock solutions of Q[8] $\left(1.00 \times 10^{-4} \mathrm{~mol} \cdot \mathrm{L}^{-1}\right)$, acridine hydrochloride $\left(\mathrm{AC}, 1.00 \times 10^{-3} \mathrm{~mol} \cdot \mathrm{L}^{-1}\right)$ and $L$-amino acids $\left(2.00 \times 10^{-2} \mathrm{~mol} \cdot \mathrm{L}^{-1}\right)$ were prepared using doubly-distilled water. The test solutions were prepared by diluting the stock solutions to the required concentrations. 
Aqueous solutions of $\mathbf{A C}\left(2.0 \times 10^{-5} \mathrm{~mol} \cdot \mathrm{L}^{-1}\right)$ were prepared by diluting the stock solutions. For the absorption and fluorescence spectra, increasing concentrations $\left(0-3.0 \times 10^{-5} \mathrm{~mol} \cdot \mathrm{L}^{-1}\right)$ of $\mathrm{Q}[8]$ solution were added to the free $\mathbf{A C}$ and the $\mathrm{pH}$ was adjusted to 4.0 via the addition of concentrated hydrochloric acid. Aqueous solutions of the $\mathbf{A C} / \mathrm{Q}[8]$ complex (AC: $2.0 \times 10^{-5} \mathrm{~mol} \cdot \mathrm{L}^{-1}$ ) were prepared for characterization by fluorescence emission spectroscopy. To obtain fluorescence spectra, known concentrations of amino acids were added to the AC/Q[8] complex. Fluorescence spectra were obtained by excitation at $346 \mathrm{~nm}$ with $5 \mathrm{~nm}$ emission and excitation bandwidths, and the emission intensity was monitored at $478 \mathrm{~nm}$ at ambient temperature. The maximum emission wavelength was $\lambda \mathrm{em}=478 \mathrm{~nm}$ for the $\mathrm{AC} / \mathrm{Q}[8]$ complex. To obtain titration fluorescence spectra, $L$-Phe $(1.5,3.0,4.5 \cdots \cdots 45.0 \mu 1$, $\left.2.00 \times 10^{-2} \mathrm{~mol} \cdot \mathrm{L}^{-1}\right)$ was added to the Q[8]-AC $\left(3 \mathrm{~mL}, 2.00 \times 10^{-5} \mathrm{~mol} \cdot \mathrm{L}^{-1}\right)$ complex in quartz cells.

\section{3 ${ }^{1} \mathrm{H}$ NMR measurements}

The ${ }^{1} \mathrm{H}$ NMR spectra were recorded at $25^{\circ} \mathrm{C}$ on a JEOL JNM-ECZ400s spectrometer. $\mathrm{D}_{2} \mathrm{O}$, adjusted to $\mathrm{pH} 4$ via addition of $\mathrm{DCl}$, was used as a field-frequency lock. The observed chemical shifts are reported in parts per million (ppm) relative to that of the internal tetramethylsilane (TMS) standard (0.0 ppm).

\subsection{Synthesis of guest $A C$}

Acridine $(358 \mathrm{mg}, 0.002 \mathrm{~mol})$ was dissolved in concentrated $\mathrm{HCl}(10 \mathrm{~mL})$, and the solution was then stirred under an inert nitrogen atmosphere, and heated to $80{ }^{\circ} \mathrm{C}$ and refluxed for a further $6 \mathrm{~h}$. The resulting solution was spin-dried and the yellow precipitate was washed with diethyl ether and dried in vacuo to afford AC (366 mg, 85\%). ${ }^{1} \mathrm{H}$ NMR $\left(\mathrm{D}_{2} \mathrm{O}, 400 \mathrm{MHz}\right) \delta 9.74(\mathrm{~s}, 1 \mathrm{H}), 8.37(\mathrm{~d}, \mathrm{~J}=8.6 \mathrm{~Hz}, 2 \mathrm{H}), 8.22-8.15$ $(\mathrm{m}, 4 \mathrm{H}), 7.83(\mathrm{~d}, \mathrm{~J}=8.3,6.0 \mathrm{~Hz}, 2 \mathrm{H})$. Anal. Calcd. for $\mathrm{C}_{13} \mathrm{H}_{10} \mathrm{NCl}$ : C, 72.40; H, 4.67; $\mathrm{N}, 6.49$; found $\mathrm{C}, 72.07 ; \mathrm{H}, 4.81 ; \mathrm{N}, 6.52$.

\subsection{Crystallization and structure determination}

Synthesis of the inclusion complex Q[8]-AC (CCDC 1962675) Q[8] (7.54mg, $0.005 \mathrm{mmol}), \mathbf{A C}(10.78 \mathrm{mg}, 0.050 \mathrm{mmol})$ and $\mathrm{CdCl}_{2} \cdot 4 \mathrm{H}_{2} \mathrm{O}(11.8 \mathrm{mg}, 0.051 \mathrm{mmol})$ were dissolved in $\mathrm{HCl}(4 \mathrm{~mL}, 6 \mathrm{~mol} / \mathrm{L})$. The mixture was heated until complete dissolution. Slow evaporation of the volatiles from the solution over a period of about two weeks provided buff colored crystals.

Synthesis of the inclusion complex Q[8]-L-Phe (CCDC 1962676) Q[8] (7.54mg, $0.005 \mathrm{mmol}), L$-Phe $(8.26 \mathrm{mg}, 0.050 \mathrm{mmol})$ and $\mathrm{CdCl}_{2} \cdot 4 \mathrm{H}_{2} \mathrm{O}(11.8 \mathrm{mg}$, $0.051 \mathrm{mmol})$ were dissolved in $\mathrm{HCl}(4 \mathrm{~mL}, 6 \mathrm{~mol} / \mathrm{L})$. The mixture was heated until complete dissolution. Slow evaporation of the volatiles from the solution over a period of about two weeks provided colorless crystals.

All structure determination details are presented in Table S3, ESI.

Diffraction data for the complexes were collected at $298 \mathrm{~K}$ with Bruker D8 VENTURE diffractometer and Bruker SMART Apex-II CCD diffractometer.

\section{Conclusions}


In summary, a new "on-off-on" fluorescent chemosensor based on cucuribit[8]uril (Q[8]) and acridine hydrochloride (AC) has been successfully constructed and utilized for the recognition of different amino acids. In aqueous solution, AC was encapsulated within the Q[8] cavity to form a 1:2 host-guest inclusion complex, which was verified in the solid-state by a single-crystal X-ray structural determination. Free AC is known to be strongly fluorescent, however this strong fluorescence was extinguished in the Q[8]-AC inclusion complex. This non-fluorescent Q[8]-AC complex served as a fluorescence "off-on" probe capable of recognizing $L$-Phe or $L$-Trp, owing to the competitive interaction between $L$-Phe or L-Trp; the included AC molecule is replaced by the $L$-Phe or $L$-Trp molecule in the $\mathrm{Q}[8]$ cavity. This fluorescent chemosensor also possessed $\mathrm{pH}$-responsiveness, where the addition of basic $L$-amino acids ( $L$-Arg, $L$-His or $L$-Lys) caused blue shift fluorescence changes for the $\mathrm{Q}[8]-\mathrm{AC}$ complex. This work led to a fluorescence method for the detection of five amino acids in a single system. The method presented in this investigation represents a promising potential practical application for the detection of amino acids.

\section{Acknowledgements}

We thank the National Natural Science Foundation of China (NSFC no 21861011), the Major Program for Creative Research Groups of Guizhou Provincial Education Department (2017-028) and the Innovation Program for High-level Talents of Guizhou Province (No. 2016-5657) are gratefully acknowledged for financial support. CR thanks the EPSRC for an Overseas Travel Grant (EP/S025537/1).

\section{Conflicts of interest}

There a no potential conflict of interest reported by the authors.

\section{References}

[1] S. Berliner, Advance for Nurse Practitioners. 14 (2006) 47-48.

[2] V.I. Chalova, I.B. Zabala-Diaz, C.L. Woodward, S.C. Ricke, World J. Microbiol. Biotechnol. 24 (2007) 353-359.

[3] S. Kado, H. Otani, Y. Nakahara, K. Kimura, Chem. Commun. 49 (2013) 886-888.

[4] V.K. Gupta, A.K. Jain, G. Maheshwari, H. Lang, Z. Ishtaiwi, Sensor Actuat B-Chem. 117 (2006) 99-106.

[5] R.N. Goyal, V.K. Gupta, N. Bachheti, Anal. Chim. Acta. 597 (2007) 82-89.

[6] R.N. Goyal, V.K. Gupta, S. Chatterjee, Biosens. Bioelectron. 24 (2009) 1649-1654.

[7] R.N. Goyal, V.K. Gupta, Chatterjee, Electrochim. Acta. 53 (2008) 5354-5360. 
[8] F. Schneider, Angew. Chemie Int. Ed. Engl. 17 (1978) 583-592.

[9] J. Maeda, M. Higashiyama, A. Imaizumi, T. Nakayama, H. Yamamoto, T. Daimon, M. Yamakado, F. Imamura, K. Kodama, BMC Cancer. 10 (2010) 690.

[10] Y. Miyagi, M. Higashiyama, A. Gochi, M. Akaike, T. Ishikawa, T. Miura, N. Saruki, E. Bando, H. Kimura, F. Imamura, M. Moriyama, I. Ikeda, A. Chiba, F. Oshita, A. Imaizumi, H. Yamamoto, H. Miyano, K. Horimoto, O. Tochikubo, T. Mitsushima, M. Yamakado, N. Okamoto, PLoS One. 6 (2011) e24143.

[11] H.J. Kim, S.H. Jang, J.S. Ryu, J.E. Lee, Y.C. Kim, M.K. Lee, T.W. Jang, S.Y. Lee, H. Nakamura, N. Nishikata, M. Mori, Y. Noguchi, H. Miyano, K.Y. Lee, Lung Cancer. 90 (2015) 522-527.

[12] X. Bi, C.J. Henry, Nutr. Diabetes. 7 (2017) e249.

[13] E. Simin' ska, M. Koba, Amino Acids. 48 (2016) 1339-13452.

[14] H. Yoshida, Y. Nakano, K. Koiso, H. Nohta, J. Ishida, M. Yamaguchi, Anal. Sci. 17 (2001) 107-112.

[15] D. Wellner, A. Meister, Annu. Rev. Biochem. 50 (1981) 911-968.

[16] P. Felig, Annu. Rev. Biochem. 1975, 44, 933-955.

[17] C. Hirayama, K. Suyama, Y. Horie, K. Tanimoto, S. Kato, Biochem. Med. Metab. Biol. 38 (1987) 127-133.

[18] Y.M. Fu, H. Zhang, M.J. Ding, Y.Q. Li, X. Fu, Z.X. Yu, G.G. Meadows, J. Cell. Physiol. 209 (2006) 522-534.

[19] A.K. Saini, M. Saraf, P. Kumari, S.M. Mobin, New Journal of Chemistry. 42 (2018) 3509-3518.

[20] S. Russo, I.P. Kema, R.M. Fokkema, J.C. Boon, P.H.B. Willemse, E.G.E. de Vries, J.A. Den Boer, J. Korf, Psychosomatic Medicine. 65 (2003) 665-671.

[21] R.S. Staden, R.M. Nejem, J.F. Staden, H.Y. Aboul-Enein, Biosens. Bioelectron. 35 (2012) 439-442.

[22] M. Ebata, Y. Takahashi, H. Otsuka, J. Chromatogr. A. 25 (1966) 1-10.

[23] V.K. Gupta, A.K. Singh, M.A. Khayat, B. Gupta, Anal. Chim. Acta. 590 (2007) $81-90$.

[24] R.J. DeLange, D.M. Fambrough, E.L. Smith, J. Bonner, J. Biol. Chem. 243 (1968) 5906-5913.

[25] P. Das, A.K. Mandal, R.G. Upendar, M. Baidya, S.K. Ghosh, A. Das, Org. Biomol. Chem. 11 (2013) 6604-6614. 
[26] H.S. Jung, J.H. Han, T. Pradhan, S. Kim, S.W. Lee, J.L. Sesslerc, T.W. Kim, C. Kang, J.S. Kim, Biomaterials. 3 (2012) 945-953.

[27] T. Matsumoto, Y. Urano, T. Shoda, H. Kojima, T. Nagano, Org. Lett. 9 (2007) 3375-3377.

[28] R.N. Dsouza, U. Pischel, W.M. Nau, Chem. Rev. 111 (2011) 7941-7980.

[29] L. You, D. Zha, E.V. Anslyn, Chem. Rev. 115 (2015) 7840-7892.

[30] W.L. Mock, N.Y. Shih, J. Am. Chem. Soc. 110 (1988) 4706-4710.

[31] J.W. Lee, S. Samal, N. Selvapalam, H.J. Kim, K. Kim, Acc. Chem. Res. 36 (2003) 621-630.

[32] R.H. Gao, L. X. Chen, K. Chen., Z. Tao, X. Xiao, Coordin. Chem. Rev., 348 (2017) 1-24.

[33] D. Bai, X. Wang, Z.Z. Gao, S.C. Qiu, Z. Tao, J.X. Zhang, X. Xiao, Chin. J. Org. Chem. 37 (2017) 2022-2027.

[34]J.J. Lian, P. Liu, X.C. Li, L.N. Gao, X.L. Luo, X. Zhang, Z.Q. Shi, Q.Y. Liu, Appl. Organomet. Chem. (2019) e4884.

[35] Y. Gao, C. Jin, X. Li, K. Wu, L. Gao, X. Lyu, X. Zhang, X. Zhang, X. Luo, Q. Liu, Colloid Surface A, 568 (2019) 248-258.

[36] J. Lagona, P. Mukhopadhyay, S. Chakrabarti, L. Isaacs, Angew. Chem. Int. Ed. 44 (2005) 4844-4870.

[37] S.M. Liu, C. Ruspic, P. Mukhopadhyay, S. Chakrabarti, P.Y. Zavalij, L. Isaacs, J. Am. Chem. Soc. 127 (2005) 15959-15967.

[38] X.Yu. Deng, K. Chen, M.D. Chen, L.B. Lü, Z. Tao. Eur. J. Inorg. Chem. 9 (2019) 1212-1219.

[39] X.Y. Deng, W.T. Xu, M. Liu, M.X. Yang, Q.J. Zhu, B. Lü, Z. Tao, Supramolecular Chemistry, 31 (2019) 616-624.

[40] L.A. Logsdon, A.R. Urbach, J. Am. Chem. Soc. 135 (2013) 11414-11416.

[41] M.V. Rekharsky, H. Yamamura, Y.H. Ko, N. Selvapalam, K. Kim, Y. Inoue, Chem. Commun. 19 (2008) 2236-2238.

[42] P.H. Shan, S.C. Tu, R.L. Lin, Z. Tao, J.X. Liu, X. Xiao, CrystEngComm, 19 (2017) 2168-2171.

[43] O. Danylyuk, CrystEngComm, 19 (2017) 3892-3897.

[44] J. Lee, L. Perez, Y. Liu, H. Wang, Richard J. Hooley, W.W. Zhong, Anal. Chem. 90 (2018) 1881-1888.

[45] L.C. Smith, D.G. Leach, B.E. Blaylock, O.A. Ali, A.R. Urbach, J. Am. Chem. 
Soc. 137 (2015) 3663-3669.

[46] P.H. Shan, J. Zhao, X.Y. Deng, R.L. Lin, B. Bian, Z. Tao, X. Xiao, J.X. Liu, Analytica Chimica Acta 1104 (2020) 164-171.

[47] M.X. Yang, M. Liu, M. Yang, Q. Wang, X. Zeng, Z. Tao, X. Xiao, Y. Huang, Inorganic Chemistry Communications 108 (2019) 107514-107522.

[48] P. Rajgariah, A. R. Urbach, J. Incl. Phenom. Macrocycl. Chem. (2008) 251-254.

[49] M del. Pozo, P. Hernandez, L. Hernandez, C. Quintana, J. Mater. Chem. 21 (2011) 13657-13663.

[50] Q.H. Bai, S.W Zhang, H.R. Chen, T. Sun, C. Redshaw, J.X. Zhang, X.L. Ni, G. Wei, Z. Tao, ChemistrySelect, 2 (2017) 2569-2573.

[51] X.K. Yu, W.T. Liang, Q.F. Huang, W.H. Wu, Jason J. Chruma, C. Yang, Chem. Commun. 55 (2019) 3156-3159.

[52] P. Wang, Y. Yao, M. Xue, Chem. Commun. 50 (2014) 5064-5067. 